\title{
Prevalence of Primary Dysmenorrhea Among Secondary Girl Students at Assiut City
}

\author{
Shaimaa Mohammed Goda ${ }^{1}$, Safaa Ahamed Mohamed ${ }^{2}$, Asmaa Kamal Hassan ${ }^{3}$ \& Naglaa Saad Abd El-Aty. \\ 1. Assistant lecture in family and Community Health Nursing Faculty of Nursing-Assuit University, Egypt. \\ 2. Professor of family and Community Health Nursing Faculty of Nursing - Assuit University, Egypt. \\ 3. Assistant Professor in family and Community Health Nursing Faculty of Nursing-Assuit University, Egypt.
}

\begin{abstract}
Adolescence is a significant period characterized by growth, developmental, needs and rights. Dysmenorrhea is a severe, painful, cramping sensation in the lower abdomen and has different detrimental effects on females and the community. The study aimed to determine the prevalence of dysmenorrhea among secondary girl Students. Subject and Methods: Descriptive cross sectional research design was used in this study. It was conducted in four secondary girl schools at Assiut city by using multi stage random sample of 666 students who participated in the study, while the girl students having dysmenorrhea represent 515.Three tools were used for data collection, first tools: A structured self-administered questionnaire which consisted of two parts: part I: included personal characteristics, part II: knowledge about menstruation and dysmenorrhea .Second tools: Verbal Multidimensional Scoring System (VMS). Third tools: Visual Analogue scale used to assess the severity of dysmenorrhea. Results: The mean age of studied students \pm SD was $16.31 \pm 0.91(15.0-19.0)$, more than two thirds (77.3\%) of them suffering from dysmenorrhea. Conclusion: More than three quarters of secondary girl students suffering from dysmenorrhea Recommendation: Increase awareness of students regarding menstruation and dysmenorrhea through mass media. Health education program to students, teacher and school health nurses about menstruation, dysmenorrhea and how to relive pain.
\end{abstract}

\section{Keywords: Prevalence, Adolescent \& Primary Dysmenorrhea.}

\section{Introduction}

Adolescence is a transition period from childhood to adulthood and is characterized by major natural changes like physical, sexual and psycho-social growth. As the direct reproducers of future generations ,the health of adolescent girls influences not only their own health, but also the health of the future off spring (Kar, et al., 2015).

Dysmenorrhea or painful menses is the most common gynecological diseases in females reproductive period. It is a painful or cramping feeling in the lower abdomen often complemented by other biologic signs, including fatigue, dizziness, sweating, headaches, backache, nausea, vomiting, diarrhea,all occurring just before or during the menses (Alghamdi, 2019).

There are two types of dysmenorrhea; primary dysmenorrhea which is a pain with no obvious pathological cause usually begin during adolescence; while, secondary dysmenorrhea is menstrual pain associated with underlying pathology, and it is more common in women older than 20 years (Giletew \& Bekele, 2018)

Increasing production and release of prostaglandins during menstruation by the endometrium causes hyper-contractility of the uterus, leading to uterine hypoxia and ischemia, which are accepted to cause the pain and cramps in primary dysmenorrhea (Shaviv etal., 2018).

Dysmenorrhea is a cause of recurrent short-term school absenteeism in females of reproductive age. It is a negative result of dysmenorrhea and has been steady with examinations that have tended to this problem in adolescents and young adults. Through the days of menstrual bleeding, at least one out of three young women had to be absent due to the intensity of the pain or expressed their limitation to do daily activity(Teheran et al., 2018).

School Nurses are in a special position for educating adolescent girls about menarche, menstruation, other health concepts and practices related to female reproductive health. Education and support can help adolescent girls progress a positive approach toward their symptoms, learn constructive ways of managing them, and get assurance and support from their family and friends (Kyilleh et al., 2018).

\section{Significant of the study}

Primary dysmenorrhea is a painful menstruation that occurs in the absence of any significant pelvic pathology. It usually develops after first two years of the menarche. it is one of most common problem among adolescents and the 
typical age range of occurrence for primary dysmenorrhea is between 17 and 22 years (Mole, 2017, Renuka \& Jeyagowri, 2015)

In Egypt, it was reported a high prevalence rate of dysmenorrhea $(66.0 \%)$ with $(28.4 \%)$ for mild pain, $24.3 \%$ for moderate pain and $13.3 \%$ for severe pain (Nooh, 2016)

Dysmenorrhea is frequently associated with sickness absenteeism, decrease in academic performance, and decrease in physical and social activities in adolescents. In spite of the frequency and severity of dysmenorrhea, most girls do not seek medical treatment for this condition because they feel it is a normal part of the menstrual cycle. Therefore, dysmenorrhea affects not only the untreated person but also her family, her social life, and national economics as well.(Kumar et al., 2016)

\section{Aim of the study}

To identify the prevalence of dysmenorrhea among secondary girl students at Assiut City

\section{Research hypotheses}

Dysmenorrhea more prevalent among secondary girl students at Assiut city

\section{Subject \& Methods \\ Research design}

Descriptive cross sectional research design was used in this study

\section{Setting of the study}

Assiut city includes (7) governmental secondary girls school included (8049) students which divided into east (3) and west (4). The study was conducted on randomly four secondary girls schools at Assiut city, two of them were general secondary schools, namely (El- waledia secondary girls, El khayat secondary school girls ) and two were technical secondary schools namely (Industrial secondary school girls, Secondary commercial Girls

\section{Sample}

Multi stage random sample was used in this study, First stag: (5) Were general secondary girls schools included (3300) represented $(41 \%)$ of total number of Assiut secondary schools and (2) technical secondary girls schools included (4749) students, represented (59\%) of total number of students in Assiut secondary girls schools. four secondary governmental schools for girls were selected randomly .The total number of students in selected randomly schools were (6301) students. Total number of students in selected technical schools was(4749)students, represented about $(75.4 \%)$ of total number of students in the sample while the total number of students in selected general secondary school was(1552 ) students, represented about $(24.6 \%)$ of total number of students in the sample

Second stage: Total number of girls students in Assiut schools were(8049).with software EPI /Info, version, 3 with $99 \%$ confident interval (CI) and use the prevalence of dysmenorrhea under study (66\%) included in the calculation. The sample size found to be (555) and increase $20 \%$ to avoid drop out and refuse .The final sample size was be 666 students and whom selected randomly from each grade. Proportion sample distributed to each school according to number each school

\begin{tabular}{|c|c|c|c|}
\hline School name & $\begin{array}{c}\text { Total } \\
\text { number } \\
\text { students }\end{array}$ & $\begin{array}{c}\text { Sample } \\
\text { size }\end{array}$ & Percent \\
\hline $\begin{array}{c}\text { El khayat } \\
\text { secondary school } \\
\text { girls }\end{array}$ & 1007 & 107 & $16 \%$ \\
\hline $\begin{array}{c}\text { El-waledia } \\
\text { secondary girls }\end{array}$ & 545 & 57 & $8.6 \%$ \\
\hline $\begin{array}{c}\text { Industrial } \\
\text { secondary school }\end{array}$ & 1500 & 158 & $23.8 \%$ \\
\hline $\begin{array}{c}\text { Secondary } \\
\text { commercial Girls }\end{array}$ & 3249 & 344 & $51.6 \%$ \\
\hline Total & 6301 & 666 & $100 \%$ \\
\hline
\end{tabular}

After calculation of the sample the classes were selected randomly by using systematic random sample. All grades (first, second and third grade) were included in the study.

\section{Exclusion criteria}

1. Adolescent girls with irregular menstrual periods.

2. Adolescent girls who were following any other pharmacological drugs.

3. Adolescent girls with regular physical exercise

Tools of the study:

Two tools were used to collect data for this study: Tool I: A structured self-administered questionnaire: It was designed and developed by the researchers after reviewing of different researches. It was covered two parts: Part1: Personal characteristics for students as: name ,age, academic year, school type, residence, father's education ,mother's education ,fathers' occupation ,mothers' occupation

Part 2: knowledge about menstruation and dysmenorrhea of adolescent girls about the following:-

1. Menstrual history as age of menarche, duration of menstruation, menstrual interval, regularity of menstruation, the number of pads used per day, type of pad used (El-Hameed , 2011).

2. History of dysmenorrhea and Pain associated menstruation (Gebeyehu et al., 2017, Aboushady \& El-saidy, 2016).

Tools (II): Verbal Multidimensional Scoring System(VMS) for assessment the severity of dysmenorrhea, The scoring system ranges from 0-3 
grade for evaluating the pain effect to working ability ,the systemic symptoms and whether analgesia is required or not (Direk \& khosravi ,2012).

Tools (III): Visual Analogue scale used for assessment of dysmenorrhea severity, $10 \mathrm{~cm}$ blank line used to describe the extremes of pain. The adolescent females were asked to place mark on the line that indicate the pain experienced. The scoring system ; zero $(0)$ indicate no pain, graded from $1-3 \mathrm{~cm}$ reflect mild pain ,graded from $4-7 \mathrm{~cm}$ for moderate pain and graded from $8-10 \mathrm{~cm}$ for severe pain (Aboushady \& El-saidy, 2016) .

\section{Validity}

The tools were transferred to Arabic language and reviewed to ascertain their validity by five experts in medical and nursing sciences, who reviewed the instrument for clarity, relevance, comprehensiveness, understanding and applicability.

\section{Reliability}

A reliability test was carried out by the researcher in order to examine the internal consistency of its questions. it was done during the pilot study before starting of data collected on $10 \%$ (67) of adolescent students. The value of Cronbach's alpha was $=0.834$ for knowledge

\section{Ethical consideration}

The researcher followed all the ethical issues in conducting the research. Consent was secured orally from the participants who were willing to participate in the study. The participants were informed that participation in this study is voluntary; they can withdraw at any time during the study without giving reasons. The researcher have explained the aim of the study to all school students in the study sample .They reassured that any obtained information would be strictly confidential.

The study phases

\section{1-Administrative phase}

An official approval letter was obtained from the Dean of the Faculty of Nursing, Assiut University to Assiut Directorate of Education and from Directorate of education to Central Agency for public mobilization and statistics after that to Centralized Management of Security. Finally, to directors of the schools. The letters included a permission to carry out the study.

\section{2- Pilot study}

Pilot study was carried out before starting of data collection on $10 \%$ of adolescent students who included in the sample. It aimed to test the clarity of the tools and estimate the required time to fill the questionnaire.

\section{3 - Data collection phase (Field work)}

An explanation of the purpose of the research was done to directors of schools and the researchers gave the directors of each setting a copy of official letter and the researchers were taking a copy of study schedule of the selected grades .Also the purpose of the study was explained to studied students to gain their cooperation before starting data collection. The researcher started to collect data from the end of September 2018 to the end of November 2018 (9 weeks) from (666) students who accepted to participated in this study then stopped and continued after mid-year vacation to first of April ,2019

The researcher introduced herself and purpose of the study then asked the studied students to participate in the study after assuring the confidentiality of their data. The self-administered questionnaire filled by the students themselves after clarify of the instruction. Filling of questionnaire taken to (20-30) minutes. The data was collected in (two days/ week) with average number 37- 42 students /day.

\section{Statistical analysis}

Data entry and data analysis were done using SPSS version 22 (Statistical Package for Social Science). Data were presented as number, percentage, mean and standard deviation. Chi-square was used to compare between qualitative variables. P-value considered statistically significant when $\mathrm{P}<0.05$. 


\section{Results}

Table (1) : Distribution of secondary girl students regarding to personal characteristics in Assuit City, 2019.

\begin{tabular}{|c|c|c|}
\hline Personal characteristics & No. (666) & $\%$ \\
\hline \multicolumn{3}{|l|}{ School Type } \\
\hline General secondary school & 164 & 24.6 \\
\hline Technical secondary school & 502 & 75.4 \\
\hline \multicolumn{3}{|l|}{ Age: (years) } \\
\hline 15 & 119 & 17.9 \\
\hline 16 & 304 & 45.6 \\
\hline $17-19$ & 243 & 36.5 \\
\hline \multicolumn{3}{|c|}{$16.31 \pm 0.91(15.0-19.0)$} \\
\hline \multicolumn{3}{|l|}{ Academic year: } \\
\hline First & 329 & 49.4 \\
\hline Second & 200 & 30.0 \\
\hline Third & 137 & 20.6 \\
\hline \multicolumn{3}{|l|}{ Residence: } \\
\hline Urban & 422 & 63.4 \\
\hline Rural & 244 & 36.6 \\
\hline \multicolumn{3}{|l|}{ Fathers' education: } \\
\hline Illiterate & 43 & 6.5 \\
\hline Read \& write & 93 & 14.0 \\
\hline Primary & 66 & 9.9 \\
\hline Preparatory & 58 & 8.7 \\
\hline Secondary & 264 & 39.6 \\
\hline University & 142 & 21.3 \\
\hline \multicolumn{3}{|l|}{ Mothers' education: } \\
\hline Illiterate & 125 & 18.8 \\
\hline Read \& write & 93 & 14.0 \\
\hline Primary & 55 & 8.2 \\
\hline Preparatory & 67 & 10.1 \\
\hline Secondary & 214 & 32.1 \\
\hline University & 112 & 16.8 \\
\hline \multicolumn{3}{|l|}{ Fathers' occupation: } \\
\hline Governmental employee & 335 & 50.3 \\
\hline Free business & 168 & 25.2 \\
\hline Skilled worker & 59 & 8.8 \\
\hline Retired & 61 & 9.2 \\
\hline \multicolumn{3}{|l|}{ Mothers' occupation: } \\
\hline Housewife & 507 & 76.1 \\
\hline Employee & 151 & 22.7 \\
\hline
\end{tabular}

*43 Fathers were dead 8 mothers were dead

Table (2):Distribution of secondary girl students regarding to their menstrual history in Assiut City, 2019

\begin{tabular}{|l|c|c|}
\hline \multicolumn{1}{|c|}{ Menstrual History } & No. (666) & \% \\
\hline Age of menarche: (years) & & \\
\hline $11-13$ & 523 & 78.5 \\
\hline $14-16$ & 143 & 21.5 \\
\hline Mean \pm SD & & \\
\hline Average menstrual period: & 28 & 4.2 \\
\hline$<3$ days & 356 & 53.5 \\
\hline 3-4 days & \multicolumn{2}{|l}{} \\
\hline
\end{tabular}




\begin{tabular}{|l|c|c|}
\hline \multicolumn{1}{|c|}{ Menstrual History } & No. (666) & \% \\
\hline 5- 7 days & 220 & 33.0 \\
\hline More than 7 days & 34 & 5.1 \\
\hline Not known & 28 & 4.2 \\
\hline Regularity of menstrual cycle: & & \\
\hline Regular & 500 & 75.1 \\
\hline Irregular & 166 & 24.9 \\
\hline Menstrual interval: & & \\
\hline$<28$ days & 95 & 19.0 \\
\hline 28- 30 days & 307 & 61.4 \\
\hline $31-35$ days & 69 & 13.8 \\
\hline$>35$ days & 29 & 5.8 \\
\hline Delayed menstrual cycle every month: & 425 & 63.8 \\
\hline Yes & 241 & 36.2 \\
\hline No & & \\
\hline Number of bads changed daily: & 545 & 81.8 \\
\hline $1-3$ & 121 & 18.2 \\
\hline$>3$ & & \\
\hline Mean \pm SD & & \\
\hline Types of towel used during menstruation: & 647 & 97.1 \\
\hline Sanitary ready towel & 10 & 1.5 \\
\hline Not reusable towel & 9 & 1.4 \\
\hline A piece of cloth to be reused after washing well and exposed to sunlight & & \\
\hline \multicolumn{2}{|l|}{$2.72 \pm 0.97(1-6)$} \\
\end{tabular}

Table (3): Distribution of the secondary girl students regarding their suffering from dysmenorrhea in Assiut City, 2019.

\begin{tabular}{|l|c|c|}
\hline \multicolumn{1}{|c|}{ Items } & No. (666) & \% \\
\hline Suffering from dysmenorrhea: & & \\
\hline Yes & 515 & 77.3 \\
\hline No & 151 & 22.7 \\
\hline Onset of dysmenorrhea: & & \\
\hline With first menstrual cycle & 315 & 61.2 \\
\hline After first menstrual cycle for six months & 117 & 22.7 \\
\hline After first menstrual cycle for one years & 50 & 9.7 \\
\hline After first menstrual cycle since two years & 33 & 6.4 \\
\hline Signs and symptoms of dysmenorrhea: & & \\
\hline Severs and persistent abdominal pain before and continuous to end of menstrual & 346 & 67.2 \\
\hline pain in the back or legs & 234 & 45.4 \\
\hline Severe headache & 120 & 23.3 \\
\hline Fever & 38 & 7.4 \\
\hline Nausea and vomiting & 43 & 8.3 \\
\hline Constipation or diarrhea & 81 & 15.7 \\
\hline Pain in the breast and lymph nodes under axilla & 33 & 6.4 \\
\hline Actions taking with symptoms: & & \\
\hline Drinking hot drinks & 341 & 66.2 \\
\hline Taking analgesics without consulting a doctor & 269 & 52.2 \\
\hline Go to sleep & 256 & 49.7 \\
\hline Practicing of exercises such as flexion of the legs on the abdomen & 68 & 13.2 \\
\hline Applying hot compresses on the abdomen or take a hot shower & 7 & 1.4 \\
\hline Go to the physician & 8 & 1.6 \\
\hline Request permission from the teacher and go home & 24 & 4.7 \\
\hline
\end{tabular}


Goda et al.,

\begin{tabular}{|l|c|c|}
\hline \multicolumn{1}{|c|}{ Items } & No. (666) & \% \\
\hline Site of pain* & & \\
\hline Lower abdomen & 481 & 93.4 \\
\hline Lower back & 269 & 52.2 \\
\hline Head & 55 & 10.7 \\
\hline Extremities & 48 & 9.3 \\
\hline Time of menstrual pain occurrence: & & \\
\hline Before menstrual cycle & 239 & 46.5 \\
\hline pain beginning and continues for 24 hours & 150 & 29.1 \\
\hline pain beginning and continues for 48 hours & 42 & 8.1 \\
\hline pain beginning and continues for end of menstrual & 84 & 16.3 \\
\hline Family history of dysmenorrhea: & & \\
\hline Yes & 294 & 57.1 \\
\hline Degree of relation:* & & \\
\hline Mother & 203 & 69.0 \\
\hline Sister & 200 & 68.0 \\
\hline Aunt & 35 & 11.9 \\
\hline Grandmothers & 16 & 5.4 \\
\hline
\end{tabular}

(*) more than one answer was selected

Table(4): Distribution of secondary girl students regarding the effect of dysmenorrhea in Assiut City ,2019

\begin{tabular}{|l|c|c|}
\hline \multicolumn{1}{|c|}{ Item } & No. (515) & \% \\
\hline Dysmenorrhea has an effect on your concentration: & & \\
\hline Yes & 379 & 73.6 \\
\hline No. of days: & & \\
\hline$<$ day & 135 & 35.6 \\
\hline 1 - days & 115 & 30.3 \\
\hline - 4 days & 83 & 22 \\
\hline All menstrual period days & 46 & 12.1 \\
\hline Dysmenorrhea leading to absence from school: & & \\
\hline Yes & 267 & 51.8 \\
\hline No. of days: & & \\
\hline$<1$ day & 104 & 38.9 \\
\hline 1 - 2 days & 117 & 43.8 \\
\hline - 4 days & 33 & 12.4 \\
\hline All menstrual period days & 13 & 4.9 \\
\hline Dysmenorrhea have effect on performance of homework: & & \\
\hline Yes & 385 & 74.8 \\
\hline No. of days: & & \\
\hline$<1$ day & 104 & 27.0 \\
\hline - 2 days & 145 & 37.7 \\
\hline - 4 days & 84 & 21.8 \\
\hline All menstrual period days & 52 & 13.5 \\
\hline
\end{tabular}




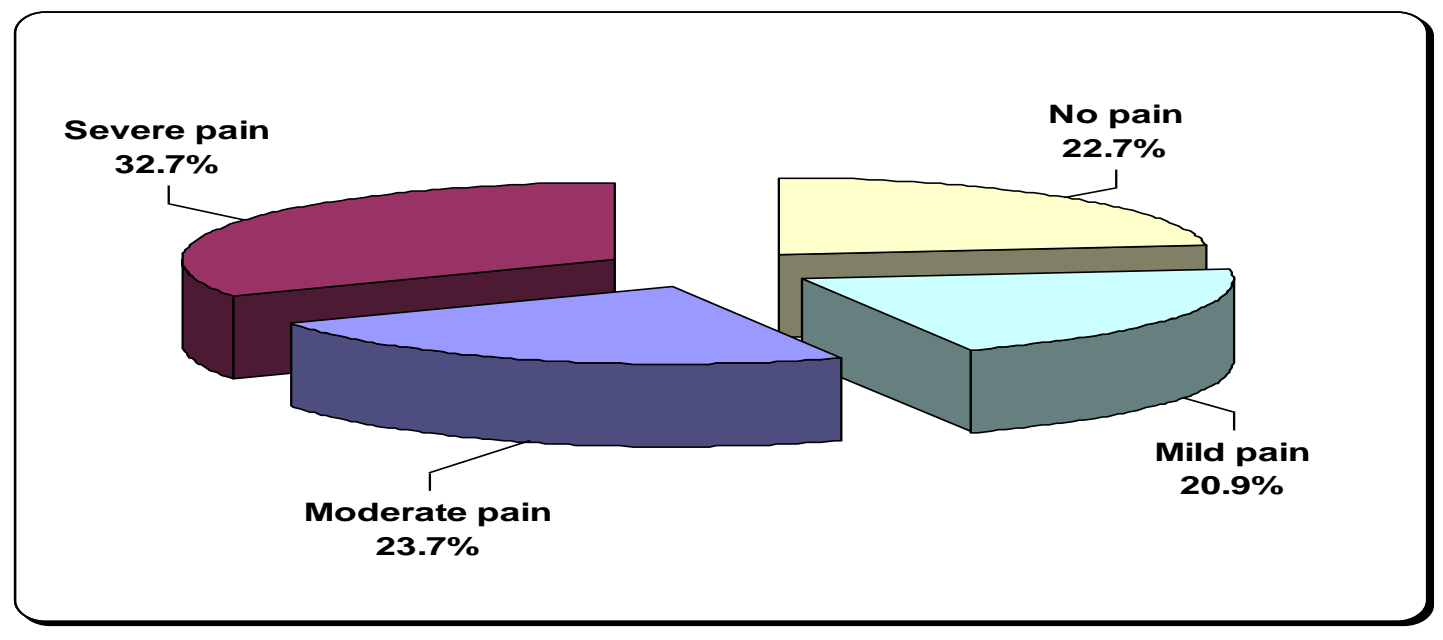

Figure(1):Distribution of secondary girl students regarding the degree of pain during dysmenorrhea in Assiut city, 2019

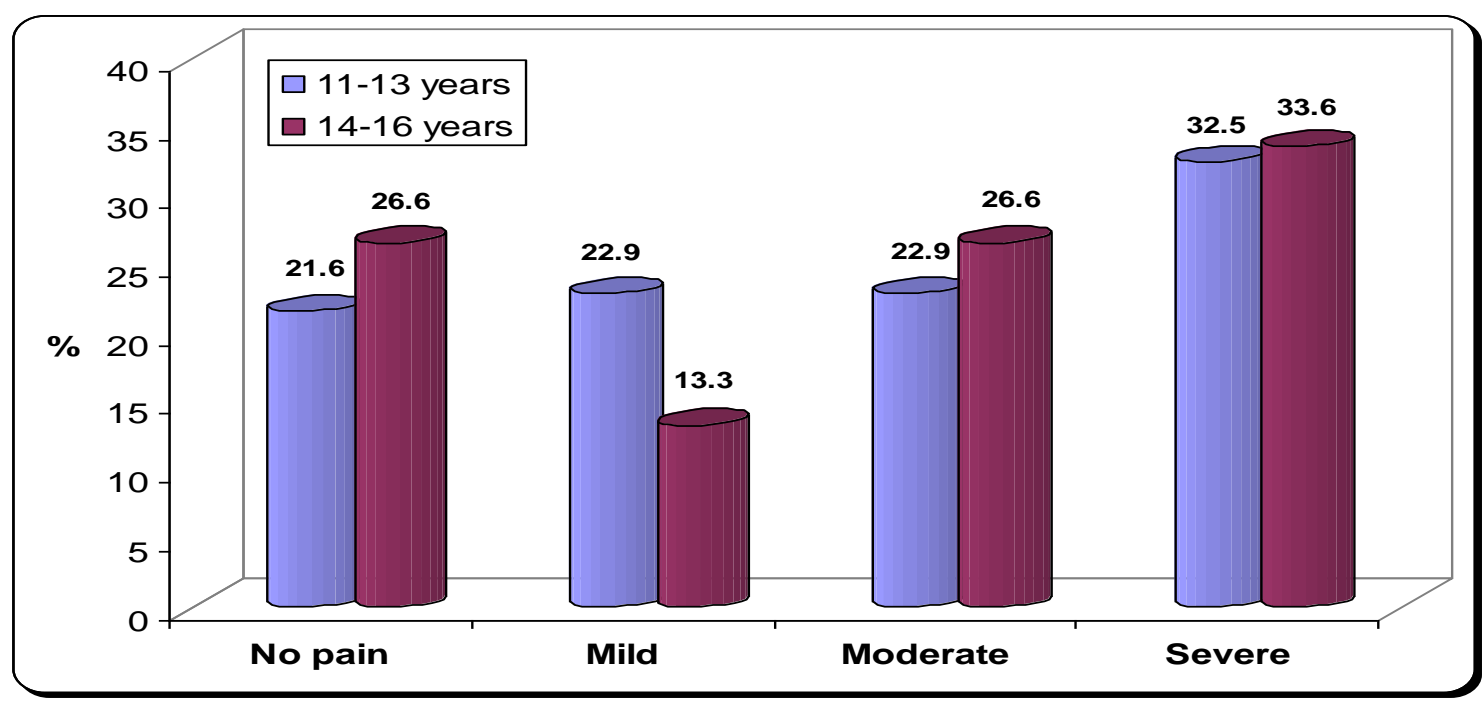

Figure (2): Relation between age of menarche and degree of pain among secondary girl students in Assiut city, 2019.

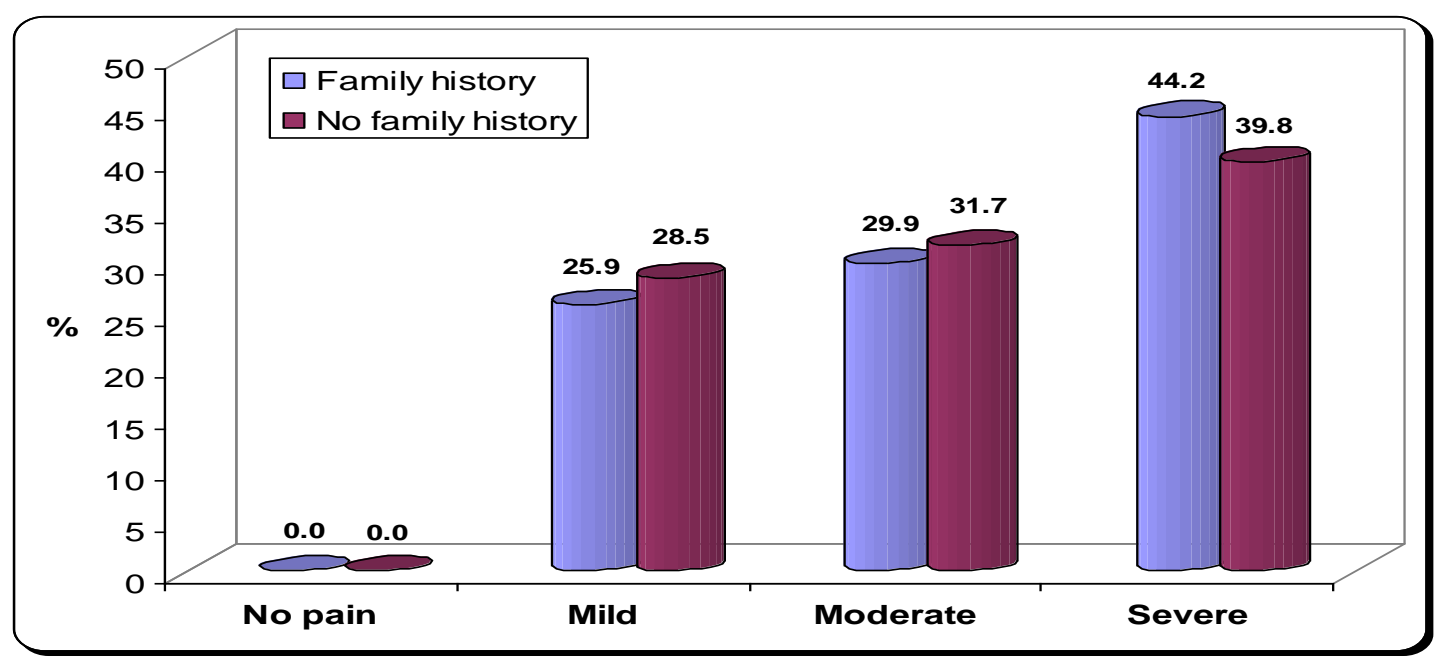

Figure (3): Relation between degree of pain and family history of secondary girl students in Assiut City,2019 
Table (1): Shows personal characteristics of secondary girl students. It was observed that the age group 16 years represent more than two fifths $(45.6 \%)$ with mean age \pm SD $16.31 \pm 0.91$ (15.019.0).Regarding to Academic year, nearly half $(49.4 \%)$ of secondary girl students were in first grade and less than one third $(30.0 \%)$ of them were in the second grade. Concerning to residence, it was found that about two thirds $(63.4 \%)$ of secondary girl students were from urban area. Also it was observed that slightly more than half $(50.3 \%)$ of students' fathers were governmental employee while, more than three quarters $(76.1 \%)$ of students' mothers were housewife.

Table (2): Illustrates that distribution of secondary girl students regarding to their menstrual history, it was revealed that more than two thirds $(78.5 \%)$ of the secondary girl students their menstruation started in age 11-13 years. Regarding to the average length of menstrual period, it was observed that more than half (53.5\%) of them their ranged from 3-4 days. Also it was found that slightly more than three quarters $(75.1 \%)$ of them had regular menstrual periods. According to number of bads changed daily, the majority $(81.8 \%)$ of secondary girl students mentioned that they used 1-3 bads per day.

Table (3): Clears that distribution of secondary girl students according to their suffering from dysmenorrhea. It was found that more than three quarters $(77.3 \%)$ of secondary girl students suffering from dysmenorrhea .Regarding to onset of dysmenorrhea, it was noticed that less than two thirds (61.2\%) of them having dysmenorrhea with first menstrual cycle .Regarding to action taking to relive dysmenorrhea found that $66.2 \%$ of secondary girl students drinking hot fluids. Also, the vast majority $(95.0 \%)$ of them didn't go to physician for menstrual pain management. Regarding to family history, it was observed that more than half $(57.1 \%)$ of secondary girl students had family history of dysmenorrhea

Table (4): Shows distribution of secondary girl students regarding the effect of dysmenorrhea, it was found that a round three quarters (73.6\%$74.8 \%$ )respectively of them mentioned that dysmenorrhea affected on their concentration and their performance of homework, while more than half $(51.8 \%)$ of them didn't go to school due to dysmenorrhea .

Figure (1): Illustrates that distribution of secondary girl students regarding the degree of pain of dysmenorrhea, $32.7 \%$ of secondary girl students suffer from severe pain and less than one quarter (20.9\%) of them reported mild pain

Figure(2): Shows relation between age of menarche and degree of pain among secondary girl students, it was revealed that more than one quarter $(26.6 \%)$ of secondary girl students who their age of menarche was 14-16 years were had moderate pain ,while( $33.6 \%$ ) of them had severe pain

Figure (3): Illustrates that relation between degree of pain and family history. It was found that more than one quarter $(29.9 \%$ ) of moderate pain and around two fifths $(44.2 \%)$ of severe pain had family history.

\section{Discussion}

Dysmenorrhea is one of most common problem among adolescent girls. Primary dysmenorrhea affects the academic performance, social and sports activities of the girl students. (Mole, 2017)

The present study shows that the age of secondary girl students ranged from 15-19 with mean \pm SD $16.31 \pm 0.91$, these results agree with kumar et al., (2016), who conducted study about dysmenorrhea among higher secondary school girls in Indian and they reported that girl students age range from 15-19 years old and the mean age of girl students was $16.78 \pm 0.90$

Concerning to Academic year, the current study showed that around half of the secondary girl students were enrolled in first year while only less than one fifth of them were attached by third year...

The current study indicated that the mean age of menarche $12.70 \pm 1.10$.This finding in accordance with Mathew et al., (2015) who carried a study about dysmenorrhea among adolescent girls in selected schools at Mangalore with view to develop , distribute an information booklet and they reported that the mean age of menarche $12.7 \pm 0.697$.

On the other hand the present findings are contrasted to Derseh et al., (2017) who carried study about the prevalence of dysmenorrhea and its effects on school Performance in Ethiopia and reported that the mean age of menorrhea was $15.1 \pm 1.79$.This explained by the effect of sociocultural factors and geographical location had some kind of difference between Egyptian and Ethiopian community.

Regarding to the average of menstrual periods and interval, it was noticed that more than half of secondary girl students had 3 to 4 menses day and less than two thirds of them had 28-30 day of duration of menstrual cycle, this finding was similar to Mathew et al., (2015) who found more than half of girl students had 3 to 4 menses day and less than two thirds of them had 28-30 day duration of menstrual cycle.

The current finding was in contrast with George et al., (2014) carried a study to dysmenorrhea among adolescent girls characteristics and symptoms experienced during menstruation, India and reported that the majority of girl students were 3to 4 day of menses and more than half of them was 28-30 day 
duration of menstrual cycle. This may be attributed to the physiological change and family history According to menstrual regularity, the present study showed that more than three quarters of secondary girl students had regular of menstrual cycle and more than fifth of them had irregular menstrual cycle.

These results were in the same line with Aboushady \& El-saidy, (2016)who study Effect of home based stretching exercise and menstrual care on primary dysmenorrhea and premenstrual symptoms among adolescent girls in Egypt found that more than three quarters of girl students was regular cycle and more than fifth of them was irregular cycle .Because the study carried out in the same age of girl students and the same environment factors exposure of them.

In contrast with study, another study conducted by Sangwan \& Vashisht, (2017) who study the Menstrual pattern and prevalence of dysmenorrhea among school going adolescent girls in a rural block of Haryana and found that the majority of girl students had regular of cycle and less than fifth of them was irregular cycle .This may be attributed to different lifestyle, dietary habits, stress and hormonal imbalance.

Regarding the number of pads changed daily and types of towel used during menstruation, the present study cleared that the majority of secondary girl students mentioned that 1-3 pads / day changed and the vast majority of them reported they used sanitary ready towel. This may be attributed to the influence of television which had increased their awareness regarding the availability and use of sanitary pads. These results disagree with Hakim et al., (2017)who study Across sectional study on the knowledge ,attitude and practices toward menstrual cycle and its problems among government and non-government adolescent school girls in India and found that more than two fifths of girl students were use sanitary pad only.

According to prevalence of dysmenorrhea, more than three quarter of secondary girl students suffering from dysmenorrhea. These results in the same line with Akbarzadeh et al., (2017) who study the relationship between age at menarche and primary dysmenorrhea in female students of shiraz schools in Iran and found more than three quarters of girl students were suffering from dysmenorrhea.

These results are disagreement with Ziba et al., (2019) who Conducted study in Ghana about dysmenorrhea and associated risk factors among adolescent girls in School and found that the majority of girl students were suffering from dysmenorrhea, it may be attributed to the associated with ethnic, sociocultural factors and geographical location

The present study showed that less than two thirds of secondary girl students are suffering from dysmenorrhea with first menstrual cycle. This results disagree with George, (2014) who reported more than two fifths of girl students were suffering from dysmenorrhea with first menstruation .

As regard to signs and symptoms of dysmenorrhea the current study showed that more than two thirds of secondary girl students were suffering from severe and persistent abdominal pain and more than two fifths of them mentioned pain in the back and legs .This explained as increases prostaglandin levels cause contraction abnormalities that occur alone or in combination including elevated basal tone, elevated active pressure and increased number of contraction per 10 minutes theses abnormalities lead to poor uterine reperfusion and oxygenation resulting in pain In the same line Bachloo et al., (2016) who study perception and practice of menstruation among school going adolescent girls in district Ambala Haryana ,India and they found that more than two thirds of girl students were suffering from abdominal pain, while it was in contrast with George et al., (2014) who found that more than two fifths of girl students were felling pain in the lower abdominal and more than three quarters of them complain from back pain

Concerning to time of pain occurrence, the present study found that more than two fifths of secondary girl students reported that the occurrence pain before menstrual cycle and agree with Rafique \& AlSheikh, (2018) who study prevalence of primary dysmenorrhea and its relationship with body mass index in Saudi Arabia found more than two fifths of girl students were started pain before day of menstrual cycle

These results disagreed with Wong, (2018) who carried study about health related quality of life among chinese adolescent girls with dysmenorrhea found slightly more than one quarter of girl students start one day before the onset of menstruation .

The present study indicated that the majority secondary girl students were reported that the lower abdomen was the site of pain. These results agreed with Mathew et al., (2015) who reported that the majority of girl students mentioned that lower abdomen was the site of pain .

The results of current study not agree with George et al, (2014) Who reported that more than one third of girl students reported that site of pain was at lower abdomen

As regard to degree of pain. The present study showed that about one third of secondary girl students suffer from severe pain and less than one quarter had mild pain .This finding contrasted with kumar, et al., (2016) who found was mild pain in about one third and about one fifth as severe pain .May be related to the existence of different cultural perception and responses to various gradients of pain. 
The present study indicated that more than half of secondary girl students had family history of dysmenorrhea, due to a genetic susceptibility of some females to dysmenorrhea and the scientific fact that family history was one of the risk factor for dysmenorrhea

According to effect of dysmenorrhea on your concentration, the current study revealed that the more than three quarters of secondary girl students reported that dysmenorrhea effect on their concentration. These results were disagreement with Femi-Agboola et al., (2017) who conducted study about dysmenorrhea , Its effects on school absenteeism and activities among adolescents in selected secondary schools in Nigeria and they reported the more than one fifth of them have loss of concentration.

The present study found that more than half of secondary girl students reported that absence from school and less than three quarters of them reported that dysmenorrhea affecting on their performance of homework. It may be attributed to hormonal disturbance during menstruation.

The present study was consistence with kumar et al., (2016) who found that more than half of their girl students were absent from school due to painful menstruation .

This result contrast with Mohammed et al., (2019) who study dysmenorrhea and associated factors among secondary school students in East Hararghe Zone, Eastern Ethiopia and reported that slightly more than two fifths of girl students were absent from school and more than one third of them their dysmenorrhea effect on homework task performance .

\section{Conclusion}

Based on the results the study, it can be concluded that: prevalence of dysmenorrhea among secondary girl students were represented more than three quarters of them

\section{Recommendations}

Based on the results of the present study, the following recommendations are suggested:

- Increases awareness of students regarding menstruation and dysmenorrhea through mass media.

- The curriculum of students should be include basic part about menstruation, dysmenorrhea, methods of management and how to relive pain

- Health education program to students, teacher and school health nurses about menstruation, dysmenorrhea and how to relive pain

- Library school should be rich with adequate arabic booklets and magazines which include materials related to menstruation and dysmenorrhea

\section{References}

1. Aboushady R., \& El-saidy T., (2016): Effect of Home based Stretching Exercises and Menstrual Care on Primary Dysmenorrhea and premenstrual Symptoms among Adolescent Girls , Journal of Nursing and Health Scince ,5 (2): $10-17$.

2. Akbarzadeh M., Tayebi N., \& Abootalebi M., (2017): The Relationship between age at menarche and primary dysmenorrhea in Female Students of Shiraz Schools, Shiraz E-Medical Journal,18(9): 14520.

3. Alghamdi F., Al-Zahrani A., \& Alabdulaziz H., (2019): Dysmenorrhea Characteristics and Self-Care Method used among Female Nursing Students at King Abdulaziz University, Journal of Gynecology and Obstetrics,7(1): 17-24.

4. Bachloo T., Kumar R., Goyal A., Singh P., Yadav S., Bhardwaj A., \& Mittal A., (2016): A study on perception and practice of menstruation among school going adolescent girls in district Ambala Haryana, India, International Journal Community Medicine Public Health,3(4):931-7.

5. Derseh B., Afessa N., Temesgen M., Semayat Y., Kassaye M., Sieru S., Gizachew S., \& Ketsela K., (2017): prevalence of dysmenorrhea and its effect on school performance in Ethiopia, Journal Women's Health Care, 6(2): 361

6. Direk V., \& Khosravi A., (2012): Comparison of verbal multidimensional scoring system (VMS) with Visual Analogue Score (VAS) for evaluating of shiraz Thymus Vulgaris on menstrual pain ,Journal of pharmaceutical and biomedical science ,23(23):1-5

7. El-Hameed N., (2011): Assessment of knowledge and Attitude toward dysmenorrhea and menstrual hygiene among adolescent girls in some nursing school at el-minia governorate submitted for partial fulfillment of the requirements of the master degree in obstetrical and gynecological nursing.

8. Femi-Agboola D., Sekoni O., \& Goodman O., (2017): Dysmenorrhea, its effect on school absenteeism and school Activities among adolescent in selected secondary schools in Ibadan ,Nigeria, Nigeria Medical journal, 58(4)143-148

9. Gebeyehu M., Mekuria A., Tefera Y., Andarge D., Yabsira Y., Bejiga G., \& Gebresillassie B., (2017): Prevalence, Impact, and Management Practice of Dysmenorrhea 
among University of Gondar Students, Northwestern Ethiopia, International Journal of Reproductive Medicine ,6(8):1-8

10. George N., Priyadarshini S., \& Shetty S., (2014) : Dysmenorrhoea among adolescent girls-characteristics and symptoms experienced during menstruation. Nitte University Journal of Health Science,4(1) 35:45

11. Giletew A., \& Bekele W., (2018): Prevalence and Associated Factors of Primary Dysmenorrhea Among Debre Tabor University Students, North Central Ethiopia, American Journal of Health Research, 4(4):70-74.

12. Hakim A., Shaheen R., \& Tak H., (2017): cross sectional study on the knowledge, attitudes and practices towards menstrual cycle and its problems: a comparative study of government and non-government adolescent school girls, International Journal Community Medicine and Public Health,4(4):973- 981

13. Kar S., Choudhury A., \& Singh A., (2015): Understanding normal development of adolescent sexuality: A bumpy ride ,Journal of human reproductive science, 8(2): 70-74.

14. Kumar K., Konjengbam S., \& Devi H., (2016): Dysmenorrhea among higher secondary schoolgirls of Imphal West district, Manipur: A cross-sectional study ,Journal of Medical Society, 30 (1)38:43

15. Kyilleh J., TabongT., \& Konlaan B., (2018): Adolescent reproductive health ,knowledge ,and factors affecting reproductive health choice ,International Healthand Human Rights, 18(6):111-123

16. Mathew A., Varghese D., Shaju M., Joseph N., \& Tamrakar A., (2015): Dysmenorrhea among Adolescent Girls in Selected Schools at Mangalore with View to Develop and Distribute an Information Booklet,Journal of Nursing and Health Science,4(1):34-39

17. Mohammed H., Hassen N., \& Musa A., (2019): Dysmenorrhea and Associated Factors among Secondary School Students in East Hararghe Zone, Eastern Ethiopia, East African Journal of Health and Biomedical Sciences, 3(1):39-48

18. Mole K., (2017): A study to assess the effectiveness of muscle stretching exercises on pain and discomfort during primary dysmenorrhea among nursing students in a selected college of nursing at Kannur, International Journal of Advanced Scientific Research,2(4):13-18

19. Nooh A., (2016): Nature and prevalence of menstrual Disorders among Tennage Female Students at Zagazing University ,Zagazig Egypt
Journal of pediatric and Adolescent Gynecology ,29(2):137-142

20. Rafique N., \& Al-Sheikh M., (2018): who study Prevalence of primary dysmenorrhea and its relationship with body mass index in Saudi Arabia, Journal of Obstetric Gynecological Reearchs,44(9): 1773-1778

21. Renuka K., \& Jeyagowri S., (2015): Stretching Exercise therapy and primary dysmenorrhea Nursing perspectives ,Journal of Nursing and Health Science ,4(3):1-4

22. Sangwan G., \& Vashisht B., (2017): Menstrual pattern and prevalence of dysmenorrhea among school going adolescent girls in a rural block of Haryana ,Global Journal of Medicine and Public Health ,6(2):1-5

23. Shaviv H., Rosen D., \& Ezra Y., (2018): Dysmenorrhea: Arandomized Controlled Clinical Trial evaluating a novel treatment approach ,obstetrics and Gynecology Journal ,5(19):1-5

24. Teheran A., Pineros L., Pulido F., \& Guatibonza M., (2018): Waildd score ,anew tool to diagnose dysmenorrhea and predict medical leave in university students, International journal of women health 10(35):45

25. Wong C., (2018): health related quality of life among chinese adolescent girl with dysmenorrhea, Reproductive health journal, 15(80):1-6

26. Ziba F., Adams Y., Dapare P., Nanoa Y., Ayalbire M., \& Baba E., (2019): Dysmenorrhea and Associated Risk Factors among Adolescent Girls in Junior High School of Upper East Region, Ghana , International Journal of Research and Reports in Gynaecology,2(1): 1-12 